\title{
Papers
}

\section{Simple detection of the 5S ribosomal RNA of Pneumocystis carinii using in situ hybridisation}

\author{
M Kobayashi, T Urata, T Ikezoe, E Hakoda, Y Uemura, H Sonobe, Y Ohtsuki, \\ T Manabe, S Miyagi, I Miyoshi
}

\begin{abstract}
Aims-To investigate the effectiveness of digoxigenin incorporated double stranded DNA probes produced by the polymerase chain reaction (PCR), for the detection of Pneumocystis carinii using in situ hybridisation (ISH).

Methods-Formalin fixed, paraffin wax embedded sections of 26 human lung samples from 11 patients with $P$ carinii pneumonia (PCP), and 15 with various types of fungal and viral pneumonia, were obtained during necropsy or transbronchial lung biopsy. Three additional PCP induced rat lung samples were also tested. PCR probes were prepared using the digoxigenin labelling mixture, and they were amplified from the DNA of a PCP induced rat lung after administration of dexamethasone, on the basis that $5 \mathrm{~S}$ ribosomal RNA sequences are identical in human and rat $P$ carinii. ISH was performed using this probe, and visualised using the digoxigenin nucleic acid detection kit. An immunohistochemical study using antihuman Pneumocystis monoclonal antibody was also carried out in parallel.

Results-ISH positively stained eight (of eight) lung necropsy specimens from patients with PCP, three (of three) transbronchial lung biopsy specimens from patients with PCP, and none of the three PCP induced rat lung specimens. In contrast, none of the specimens from patients with pneumonia caused by $A s$ pergillus sp $(\mathrm{n}=5)$, Candida sp $(\mathrm{n}=4)$, Cryptococcus sp (n=2), mucormycosis (n $=2$ ), or cytomegalovirus $(n=2)$ were positive on ISH or immunohistochemistry. Conclusions-Using a digoxigenin labelled PCR probe for the entire $5 S$ rRNA sequence in conjunction with conventional staining, ISH is highly reactive and specific for the diagnosis of PCP.

(F Clin Pathol 1996;49:712-716)
\end{abstract}

Keywords: Pneumocystis carinii, in situ hybridisation, PCR probe.

Pneumocystis carinii pneumonia (PCP) is one of the most dangerous complications in those who are immunosuppressed, including patients with AIDS. Nearly $60 \%$ of such patients sustain a PCP attack. PCP must be diagnosed rapidly, because there is currently an $80 \%$ probabilty of recovery from a single episode for patients with AIDS. ${ }^{1}$ Bronchoalveolar lavage, with or without a transbronchial lung biopsy specimen, as well as induced sputum, provide $\vec{N}$ important diagnostic material.

Both Grocott's methenamine silver nitrate stain and toluidine blue $\mathrm{O}$ stain are used to visualise $P$ carinii cysts in clinical samples. In contrast, Giemsa stain stains trophozoites and internal sporozoites, but leaves cyst walls $\mathbb{\Phi}$ unstained with a clear halo. These conventional stains are non-specific and require careful evaluation. More recently, monoclonal antibodies directed against $P$ carinii have become available, permitting the immunohistochemical staining of both cysts and trophozoites. ${ }^{2-4}$

Due to developments in DNA technology, in situ detection of micro-organisms, especially viral agents, has been successfully used in recent years. ${ }^{5}$ Several papers have reported in situ detection of $P$ carinii organisms. ${ }^{6-8}$ Previous in situ hybridisation (ISH) studies used a mixture of three biotin labelled antisense oligonucleotides as probes for the organism. ${ }^{78}$ Biotin labelling of oligonucleotides requires some technical skill, and the signal intensity is usually weak when used as a single probe.

Preparation of a PCR probe is rather simple if an appropriate set of primer pairs for amplification of the target is available. ${ }^{5}$ We selected 5 the $5 \mathrm{~S}$ ribosomal RNA (rRNA) of $P$ carinii as $N$ the target sequence, because $P$ carinii 5 S ribos- $N$ omal sequences are identical in humans and $\underset{2}{2}$ rats. ${ }^{9}$ The entire sequence is 120 base pairs 0 long and its whole sequence can be amplified easily by standard PCR; it is also the appropri- ? ate size for tissue permeabilty. Furthermore, rRNA is an optimal target for ISH, because rRNA abounds in individual cells.

To date, $P$ carinii has not been cultivated efficiently in vitro. ${ }^{10}$ Thus we used a PCP induced rat lung as the starting material for the 8 preparation of digoxigenin labelled probe. Our method has the potential for widespread use as a routine test.

\section{Methods}

HISTOLOGY SPECIMENS

Eight formalin fixed, paraffin wax embedded lung tissue samples from patients with PCP, 
three transbronchial lung biopsy samples from patients who had had a bronchoscopy, and three $P$ carinii infected rat lung tissue samples were tested. Haematoxylin and eosin staining, and conventional Grocott's methenamine silver nitrate staining, were carried out on all the samples. These sections were reviewed, and the diagnosis of PCP confirmed by two of the authors (HS and YO).

For controls, formalin fixed, paraffin wax embedded necropsy samples from patients with Aspergillus pneumonia ( $\mathrm{n}=5)$, Candida pneumonia ( $\mathrm{n}=4$ ), Cryptococcus pneumonia ( $\mathrm{n}$ $=2)$, pulmonary mucormycosis $(n=2)$, and cytomegalovirus $(\mathrm{CMV})$ pneumonia $(\mathrm{n}=2)$ were examined in parallel.

\section{PREPARATION OF SLIDES}

Sections $(4 \mu \mathrm{m})$ of formalin fixed, paraffin wax embedded tissue samples were mounted on glass slides precoated with 3-aminopropylmethoxysilane (Dako, Japan). They were dewaxed in xylene, washed with absolute ethanol, and dried in air. Slides were then heated at $95^{\circ} \mathrm{C}$ for 30 minutes in target retrieval solution (Dako, Carpinteria, USA), to expose their rRNA. Before hybridisation, they were rehydrated in $50 \mathrm{mM}$ Tris buffered saline, $\mathrm{pH} 7.6$ (TBS).

\section{PCR PROBES}

Kitada et al showed that 5S ribosomal sequences are indentical in human and rat $P$ carinii infection. ${ }^{9}$ PCP was induced in three Sprague-Dawley rats by administration of dexamethasone twice a week for six weeks, as described before. ${ }^{4}$ These animals were killed and their lungs were removed and stored at $-70^{\circ} \mathrm{C}$ until used. We amplified the whole sequence of PC 5S rRNA, a 120 base pair PCR product, from a PCP induced rat lung. DNA was extracted from stored $P$ carinii infected rat lung tissue. Briefly, minced rat lung tissue was frozen in liquid nitrogen and vortexed with 6 $\mathrm{mm}$ diameter glass beads several times. Then DNA was extracted with phenol/chroloform.

This PCR probe encompasses the entire sequence of the $5 \mathrm{~S}$ rRNA, which was sequenced by Watanabe et al. ${ }^{11}$ The upper primer was 5' AGT TAC GGC CAT ACC TCA AG 3', and the lower primer was 5' AAA GCT ACA GCA CGT CGT AT 3'. To prepare the digoxigenin labelled PCR probe, a two step PCR was carried out using a DNA thermal cycler (Perkin-Elmer Cetus, Norwalk, USA) as follows. The first round PCR amplification reaction was performed for 30 cycles in a 100 $\mu \mathrm{l}$ solution containing $10 \mathrm{mM}$ Tris- $\mathrm{HCl}$ at $\mathrm{pH}$ $8.3,50 \mathrm{mM} \mathrm{KCl}$, and $1.5 \mathrm{mM} \mathrm{MgCl}_{2}$ with 100 pmol of both primers, and $2.5 \mathrm{U} \mathrm{TaKaRa}$ Taq DNA polymerase (Takara Shuzo Co, Tokyo, Japan). Denaturation was performed at $94^{\circ} \mathrm{C}$ for 1.5 minutes, annealing was performed at $55^{\circ} \mathrm{C}$ for 2.5 minutes, and extension was performed at $72^{\circ} \mathrm{C}$ for 1.9 minutes. Second round PCR reactions were carried out in the same manner using digoxigenin DNA labelling mixture (Boehringer Mannheim GmbH, Germany) instead of dNTP solution for the incorporation of multiple digoxigenin molecules.
As a control probe, we prepared an irrelevant PCR probe based on the 5S ribosomal RNA sequence of Aspergillus flavus. ${ }^{12}$ The upper primer was 5' ACA TAC GAC CAT AGG GTG TG 3', and the lower primer was 5' ACA TAC AAC AGG AGG GAT TC 3'. DNA was extracted from mycelial mats cultured in Sabouraud's agar medium. ${ }^{13}$ The amplified product encompassing the whole $5 \mathrm{~S}$ ribosomal sequence was 121 base pairs long. Thermal cycling conditions used were 35 cycles at $94^{\circ} \mathrm{C}$ for 30 seconds, at $56^{\circ} \mathrm{C}$ for 45 seconds, and at $72^{\circ} \mathrm{C}$ for two minutes.

ISH

The PCR probe was dissolved in $6 \times$ SSC containing $5 \times$ Denhardt's solution and $10 \%$ dextran sulphate to an appropriate dilution, and applied to the glass slides. The slides were covered with a glass coverslip and heated at $95^{\circ} \mathrm{C}$ for three minutes, then kept at room temperature for one minute, and incubated at $40^{\circ} \mathrm{C}$ for 10 minutes. They were washed in six times with SSC at $37^{\circ} \mathrm{C}$ for 10 minutes, then in twice with SSC at room temperature for 30 minutes. Digoxigenin labelled hybrids were detected with anti-digoxigenin-alkaline phosphatase conjugated antibody (Boehringer Mannheim GmbH, Germany) diluted 1 in 500 for several hours, and signals were visualised by incubation overnight with a chromogen solution containing nitroblue tetrazolium salt (NBT) and 5-bromo-4-chloro-3-indolyl phosphate (BCIP). The tissues were finally washed with distilled water and mounted with Crystal mount (Biomeda, Foster City, USA).

In order to confirm the specificity of ISH, negative controls including: prior RNase treatment; use of an irrelevant probe (PCR probe encompassing 5S rDNA of Aspergillus flavus); and no probe, were analysed. RNase was purchased from Sigma Chemical Co. (St Louis, Missouri, USA) and diluted to $50 \mu \mathrm{g} / \mathrm{ml}$ in solution. Mounted sections were treated with the solution at $37^{\circ} \mathrm{C}$ for 30 minutes.

\section{IMMUNOHISTOCHEMISTRY}

Anti-human Pneumocystis mouse monoclonal antibody was purchased from Dako (Glostrup, Denmark). Dewaxed tissue sections were immersed in methanol containing $0.3 \%$ hydrogen peroxide to block endoperoxidase activities. The sections were incubated with a 1 in 40 dilution of antibody for 30 minutes at room temperature, washed three times in TBS buffer for five minutes, and stained by the streptavidin-biotin method using the Histofine SA-PO (MO) kit (Nichirei, Tokyo, Japan) according to the manufacturer's instructions. Sections were visualised by incubation with diaminobenzidine and hydrogen peroxide as the substrate solution. The slides were subsequently counterstained with methyl green, dehydrated, cleared and mounted with Eukit (O Kindler, Germany).

\section{Results}

ISH

Dark purple reaction products indicating the presence of $P$ carinii organisms were observed in all of the lung tissue specimens from patients 
diagnosed with PCP. ISH seems to highlight not only the cyst forms but also the trophozoites. In the necropsy tissue specimens numerous $P$ carinii organisms filled the alveolar space, as shown in a typical photomicrograph (fig 1A). When compared with Grocott's methenamine silver nitrate stain (fig 1B), both cysts and trophozoites were easily seen. $P$ carinii organisms were also stained in the tissue sections from patients with PCP obtained by transbronchial lung biopsy and in those from $P$ carinii infected rat lung (figs $2 \mathrm{~A}$ and $3 \mathrm{~A}$ ). Grocott's methenamine silver nitrate stain stained $P$ carinii organisms black in the corresponding areas (figs $2 \mathrm{~B}$ and $3 \mathrm{~B}$ ).

Clusters of ring-shaped organisms stained brown, demonstrating the localisation of antigen on the surface of $P$ carinii, were seen on consecutive slides in the necropsy lung and transbronchial lung biopsy tissue of patients with PCP (figs $1 \mathrm{C}$ and $2 \mathrm{C}$ ). However, $P$ carinii organisms could not be detected in $P$ carinii infected rat lung tissues by immunohistochemistry (fig 3C).
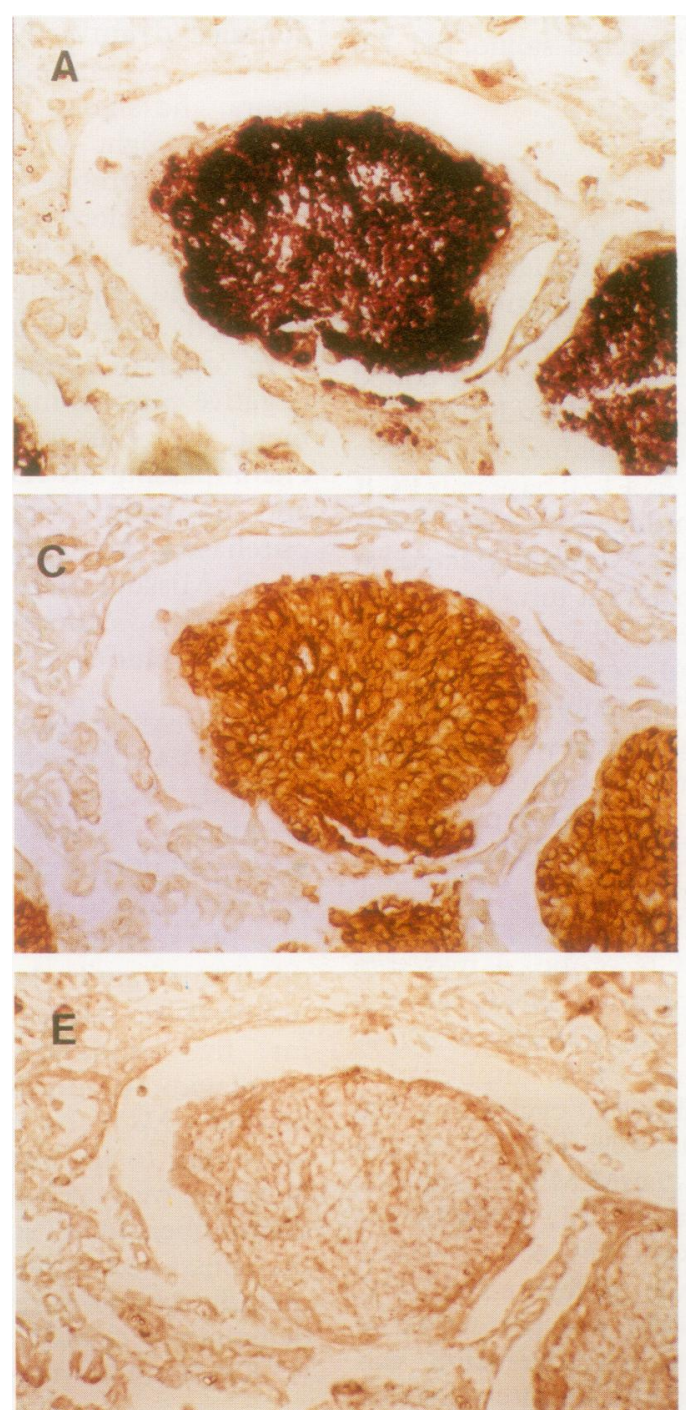

Prior treatment with RNase $(50 \mu \mathrm{g} / \mathrm{ml})$ at $37^{\circ} \mathrm{C}$ for 30 minutes completely abolished the positive reaction (fig 1D). Likewise, when slides were reacted with either an irrelevant $c$ probe derived from Aspergillus flavus, or a $\cong$ hybridisation solution lacking the probe, no reaction products were detected (figs $1 \mathrm{E}$ and $\stackrel{0}{=}$ $1 \mathrm{~F})$. ISH was carried out on consecutive $\underline{\underline{0}}$ sections in an identical manner.

ISH studies showed that $P$ carinii was $\stackrel{\overrightarrow{\vec{D}}}{\stackrel{\theta}{ }}$ present in all the necropsy lung tissue samples, 읃 transbronchial lung biopsy samples, and $P$ 흠 carinii infected rat lung tissue samples. In con- $\frac{D}{\vec{D}}$ trast, immunohistochemical studies produced $\propto$ rings of organisms stained brown, demonstrating cell surface localisation of the $P$ carinii anti- $\overrightarrow{0}$ gen, in eight out of eight necropsy samples, in $\vec{\overrightarrow{ }}$ three out of three transbronchial lung biopsy $\vec{\omega}$ samples, and in none of the three $P$ carinii $\frac{7}{0}$ infected rat lung tissue samples.

These results are shown in table $1 . P$ carinii $\frac{\overrightarrow{ }}{0}$ organisms of human origin were recognised by both ISH and immunohistochemistry (figs $1 \mathrm{~A} \overrightarrow{\mathrm{N}}$ and 1C). P carinii organisms were even identi- 음
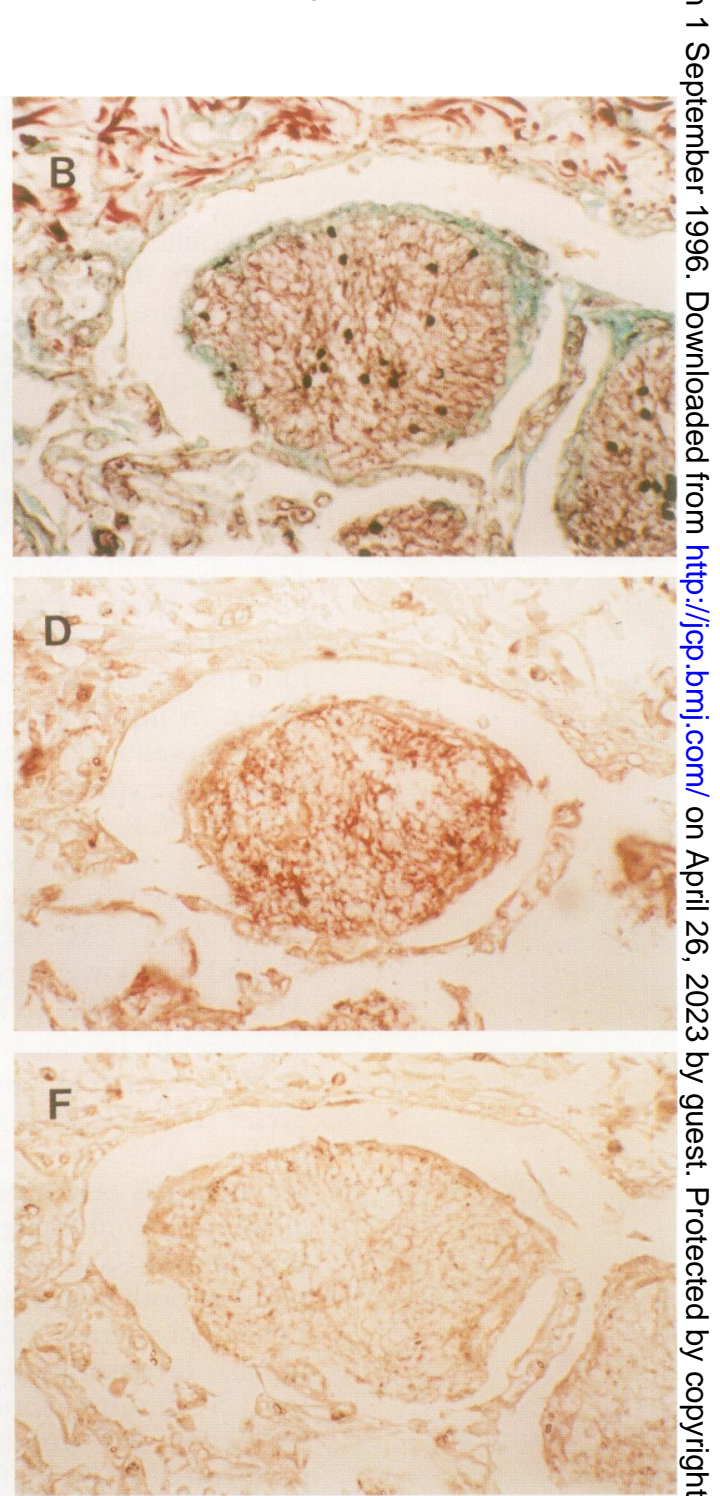

Figure 1 ISH for detection of $\mathrm{P}$ carinii in necropsied lung tissue. $\mathrm{P}$ carinii organisms were stained a dark purple colour in the alveolar space $(A)$. Grocott's methenamine silver nitrate stain showed black stained scattered $\mathbf{P}$ carinii cysts $(B)$. Immunohistochemistry using anti-human Pneumocystis monoclonal antibody resulted in brown-coloured ring-like staining, corresponding to $\mathrm{P}$ carinii organisms $(C)$. Previous treatment with RNase $(50 \mu \mathrm{g} / \mathrm{ml})$ abolished the positive reaction in ISH (D). No reaction products were detectable when the slides were reacted with an irrelevant probe: digoxigenin labelled $P C R$ probe against Aspergillus flavus $(E)$, or when the hybridisation solution contained no PCR probe $(F)$. 
fied by ISH in the small tissue samples obtained from transbronchial lung biopsies (figs $2 \mathrm{~A}$ and $2 \mathrm{C}$ ), as well as the relatively large necropsy lung tissue samples. However, $P$ carinii of rat origin were recognised by ISH, but not by immunohistochemistry (figs $3 \mathrm{~A}$ and $3 \mathrm{C})$.

In other human tissues containing various fungal and viral infections, no positively stained products were seen with ISH or immunohistochemistry. Necropsy lung tissue sections from patients with Aspergillus pneumonia $(\mathrm{n}=5)$, Candida pneumonia $(\mathrm{n}=4)$, pulmonary cryptococcosis $(n=2)$, pulmonary mucormycosis $(n=2)$, and CMV pneumonia $(n=2)$ all gave negative results.

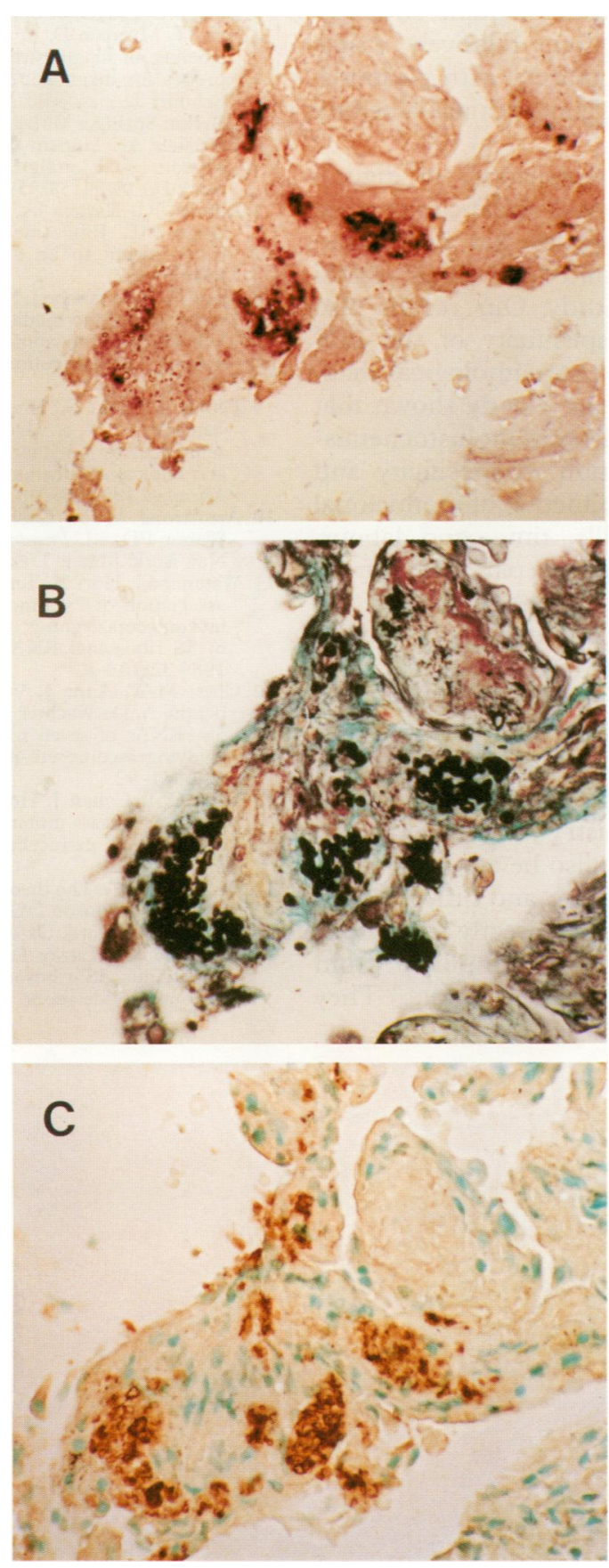

Figure 2 ISH showed $\mathrm{P}$ carinii organisms in the transbronchial lung biopsy tissue from a patient with adult $T$ cell leukaemiallymphoma complicated by $P C P(A)$. Grocott's methenamine silver nitrate stain showed $\mathrm{P}$ carini cysts in the same area (B). Immunohistochemistry showed $\mathrm{P}$ carinii organisms in a consecutive section $(C)$.
Table 1 Reactivity of in situ hybridisation (ISH) and monoclonal antibody based immunohistochemistry (IHC)

\begin{tabular}{|c|c|c|c|}
\hline Pathogen & No. positive & ISH positive & $\begin{array}{l}\text { IHC } \\
\text { positive }\end{array}$ \\
\hline \multicolumn{4}{|l|}{ Pneumocystis carinii } \\
\hline Necropsy & 8 & 8 & 8 \\
\hline $\begin{array}{l}\text { Transbronchial } \\
\text { lung biopsy }\end{array}$ & 3 & 3 & 3 \\
\hline (Infected rat lung) & (3) & (3) & $(0)$ \\
\hline Aspergillus & 5 & 0 & 0 \\
\hline Candida & 4 & 0 & 0 \\
\hline Cryptococcus & 2 & 0 & 0 \\
\hline Mucor & 2 & 0 & 0 \\
\hline CMV & 2 & 0 & 0 \\
\hline
\end{tabular}

\section{Discussion}

Molecular diagnosis has been made possible by the development of ISH and PCR techniques. In the early phase of ISH cloned fragments of complementary or genomic DNA were used in DNA-DNA or DNA-RNA hybridisation after incorporating label by nick translation. Owing to recent advances in DNA synthesis technology, oligonucleotide sequences complementary to target DNA or RNA can be easily synthesised, labelled, and used as probes, but their use in conjunction with non-isotopic detection systems has been limited. This is due to a lack
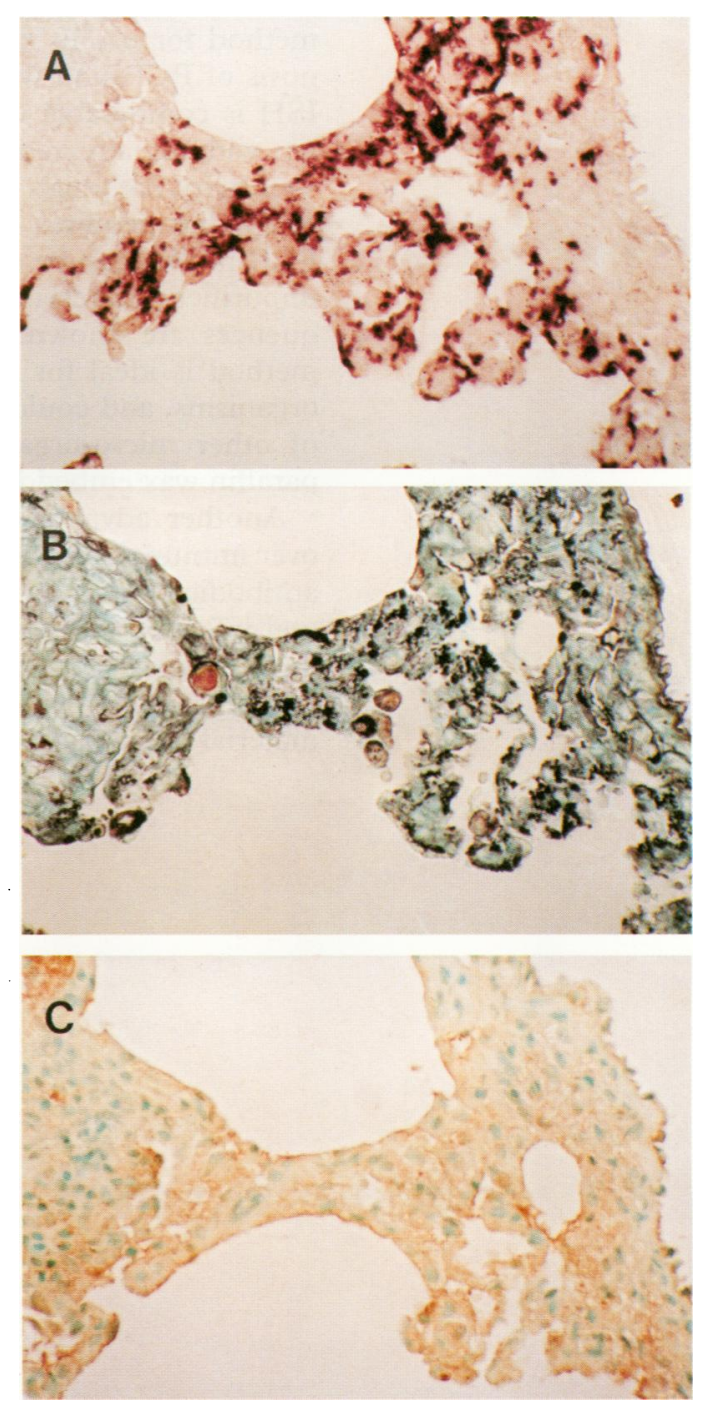

Figure 3 ISH showed $\mathrm{P}$ carinii organisms in the alveolar septa of $\mathrm{P}$ carinii infected rat lung tissue, without alveolar involvement $(A)$. Grocott's methenamine silver nitrate staining revealed $\mathrm{P}$ carinii cysts in the same area $(B)$. However, immunohistochemistry showed nothing (C).

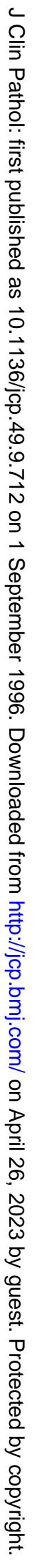


of sensitivity which results from the low amounts of label in these short sequences. To use a synthetic oligonucleotide successfully in non-isotopic methods, probe cocktails containing several sequences are required. ${ }^{14}$

Previous studies used either biotin labelled cloned DNA fragments derived from rat $P$ carinii ${ }^{6}$ or biotin labelled probe cocktails for ISH. ${ }^{78}$ Montone et al had a different approach; they elegantly synthesised terminally biotin labelled oligonucleotide probes with six biotin moieties, based on the $5 \mathrm{~S}$ rRNA sequence, and succcessfully detected Aspergillus species in formalin or Bouin's fixed, paraffin wax embedded tissue specimens using ISH. ${ }^{15}$ Preparing this kind of probe, however, is not easy. With the advent of PCR technology, amplifying and labelling single stranded and double stranded DNA probes can be done relatively easily, without using bacterial culture with plasmids, insert preparation, and conventional labelling protocols. $^{5} 14$

We have shown the superiority of digoxigenin labelled PCR probes, which can contain many digoxigenin molecules and be synthesised easily. This resulted in high signal intensity in our ISH study. Our results also seem to confirm the specificity of the ISH method for use in the histopathological diagnosis of PCP, and we have clearly shown that ISH is comparable with immunohistochemistry without any reduction in specificity and sensitivity. Although production of monoclonal antibodies requires skills, time, and labour, PCR probes can be easily prepared even from unpurified material, if DNA or RNA sequences are known. Consequently, our ISH method is ideal for the detection of $P$ carinii organisms, and could be used in the detection of other micro-organisms in formalin fixed, paraffin wax embedded human tissue sections.

Another advantage of the present method over immunohistochemistry using monoclonal antibodies is that it can also be applied to animal infection studies, as we and other groups have shown. ${ }^{6}{ }^{8}$ Kitada et al directly sequenced PCR products which were amplified from material from patients, mice, and rats. ${ }^{9}$ They found that the deduced sequences were all identical, suggesting that the $P$ carinii $5 S$ rRNA sequence is conserved in these hosts. These advantages will clearly make it easier to $c$ diagnose PCP histopathologically using ISH in $\cong$ any general laboratory environment.

1 Hopkin JM. Pneumocystis carinii. Oxford: Oxford University 으 Press, 1991:65-6.

2 Kovacs JA, Ng VL, Masur H, Leoung G, Hadley WK, Evans $\overrightarrow{\overrightarrow{7}}$ $\mathrm{G}$, et al. Diagnosis of Pneumocystis carinii pneumonia: $\stackrel{\oplus}{\rightarrow}$ improved detection in sputum with use of monoclonal antibodies. N Engl F Med 1988;318:589-93.

3 Linder E, Lundin H, Vorma H. Detection of Pneumocystis carinii in lung derived samples using monoclonal antibody $\frac{\omega}{D}$ to a $82 \mathrm{kDa}$ parasite antigen. $\mathcal{F}$ Immunol Methods $\overparen{\mathbb{D}}$ 1987;98:57-62.

4 Kobayashi M, Moriki T, Uemura Y, Takehara N, Kubonishi ڤి I, Taguchi H, et al. Immunohistochemical detection of Pneumocystis carinii in transbronchial lung biopsy speci- $\overrightarrow{0}$ mens: Antigen difference between human and rat Pneumocystis carinii. Ipn f Clin Oncol 1992;22:387-92.

5 Finckh U, Lingenfelter PA, Henne KW, Schmidt CA, Siegert W, Myerson D. In vitro amplification and digoxigenin labeling of single stranded and double stranded DNA $\frac{9}{0}$ probes for diagnostic in situ hybridization. In: Rolfs A, Schuller I, et al, eds. PCR: clinical diagnostics and research. Berlin: Springer Verlag, 1992:A37-43.

6 Wakefield AE, Hopkin JM, Burns J, Hipkiss JB, Stewart TJ, Moxon ER. Cloning DNA from Pneumocystis carinii. $\mathfrak{f} \vec{\sim}$ Infect Dis 1988;158:859-61.

7 Edman JC, Kavacs JA, Masur H, Santi DV, Elwood HJ, 응 Sogin ML. Ribosomal RNA sequence shows Pneumocystis carinii to be a member of fungi. Nature 1988; $\vec{c}$ 334:519-22.

8 Hayashi Y, Watanabe J, Nakata K, Fukayama M, Ikeda H. A $\frac{\mathbb{O}}{\mathrm{O}}$ novel diagnostic method of Pneumocystis carinii: In situ $\mathbb{D}$ hybridization of ribosomal ribonucleic acid with bioti- 3 nylated oligonucleotide probes. Lab Invest 1990;63:576- ठ 80.

9 Kitada K, Oka S, Kimura S, Shimada K, Serikawa T, Yamada J, et al. Detection of Pneumocystis carinii sequences by polymerase chain reaction: animal models 6 and clinical application to non-invasive specimens. $\mathcal{F}$ Clin Microbiol 1991;29:1985-90.

10 Armstrong MYK, Cushion MT. In vitro cultivation. In: Walzer PD, ed. Pneumocystis carinii pneumonia. 2nd edn. New York: Marcel Dekker Inc, 1994:3-24.

11 Watanabe J, Hori H, Tanabe K, Nakamura Y. Phylogenetic association of Pneumocystis carinii with the 'rhizopoda/

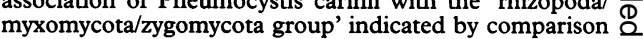
of 5 S ribosomal RNA sequences. Mol Biochem Parasitol 1989;32:163-8.

12 Chen M-W, Anne J, Volckert G, Huysmans E, Vanden- 3 berghe A, De Wachter R. The nucleotide sequences of the $5 S$ rRNAs of seven molds and a yeast and their use in studying ascomycete phylogeny. Nucleic Acids Res 1984; 12:4881-92.

13 Tang CM, Cohen J, Holden W. An Aspergillus fumigatus $\frac{\overline{0}}{0}$ alkaline protease mutant constructed by gene disruption is $\bar{\sigma}$ defficient in extracellular activity. Mol Microbiol 1992; 6:1663-71.

14 Wilkinson DG. The theory and practice of in situ hybridization. In: Wilkinson DG, ed. In situ hybridization: a practical approach. Oxford: Oxford University Press, 1992:61-73. 15 Montone KT, Litzky LA. Rapid method for detection of $\mathrm{O}$ oligonucleotide probe. Am $\mathcal{F}$ Clin Pathol 1995;103:48-51. 